\title{
Biocompatibility of anionic collagen matrices and its influence on the orientation of cellular growth
}

\section{Biocompatibilidade de matrizes de colágeno aniônico e sua influência na orientação do crescimento celular.}

\section{Rogério Leone BUCHAIM}

PhD, Department of Basic Sciences - School of Dentistry of Araçatuba - UNESP - São Paulo State University - Araçatuba - SP - Brazil

\section{Gilberto GOISSIS}

$\mathrm{PhD}$, Department of Chemistry and Molecular Physics - Institute of Chemistry of São Carlos - University of São Paulo USP - São Carlos - SP - Brazil

\section{Jesus Carlos ANDREO}

$\mathrm{PhD}$, Department of Morphology - Faculty of Dentistry of Bauru - University of São Paulo - USP - Bauru - SP - Brazil

\section{Domingos Donizeti ROQUE}

José Sidney ROQUE

Post Graduate Student - Doctor Degree - School of Medicine of Botucatu - UNESP - São Paulo State University Botucatu - SP - Brazil

\section{Daniela Vieira BUCHAIM}

Post Graduate Student - Doctor Degree - University of Sacred Heart - USC - Bauru - SP - Brazil

\section{Antonio de Castro RODRIGUES}

$\mathrm{PhD}$, Department of Morphology - Faculty of Dentistry of Bauru - University of São Paulo - USP - Bauru - Brazil

\begin{abstract}
This study aimed to analyze the biocompatibility of anionic collagen matrices, the local bone response following implantation in surgically-created bone defects, and also the influence of the collagen fiber orientation on the neoformed osseous tissue. Seventy two rats (Rattus norvegicus albinus) were used in this experiment. The animals were divided into four experimental groups: Group 1 (control), without implants; Group 2, pericardium medullar implants 12 hours; Group 3, medullar implants of tendon 24 hours, with the long axis of collagen fibers oriented parallel to the long axis of the tibia; and Group 4, medullar implants of tendon 24 hours, with the long axis of collagen fibers perpendicular to the long axis of the tibia. After the experimental surgery, the evolution of the repair process was microscopically evaluated at 7, 15, and 30 days post-surgery. The results demonstrated that the implanted matrices are biocompatible and act as a scaffold inducing bone formation, mainly in the Group 4 animals. At first, cellularity follows the arrangement of collagen fibers, later obtaining a multidirectional growth.
\end{abstract}

\section{UNITERMS}

Collagen; bone regeneration; osteogenesis; biocompatibility; tendon. 


\section{INTRODUCTION}

The destruction of bone tissue due to diseases or to incomplete bone healing after traumatic injuries can be treated by tissue engineering techniques. Growth factors, cytokine proteins, and gene therapies will be developed, which in conjunction with the appropriate carriers will regenerate bone defects or help in cases of defective healing?

Considering that most bone grafts are avascular and depend on diffusion, the size of the defect and the viability of the host can limit its applications. In large defects the grafts, may be resorbed by the body before complete osteogenesis ${ }^{9,13}$. For the autograft, there are difficulties in operational time, lack of donating regions, morbidity of the donor associated to infection, pain and hematoma ${ }^{23,26}$.

Bone tissue engineering is based on the use of a three-dimensional matrix to induce bone formation from the neighboring tissue or to act as a model for the implanted bone cells or other agents ${ }^{10}$.

Tissue engineering appeared as a promising technology to treat the loss or bad functioning of a tissue or $\operatorname{organ}^{18}$, since it does not have the limitations of current therapies. This technology is based on the observation that isolated cells will regroup in vitro in structures that are similar to the original tissue, when placed in an "appropriate medium" 14 . This "appropriate medium" corresponds to synthetic extracellular matrices, whose fundamental characteristic is a biodegradable threedimensional structure that serves as a scaffold, in vitro or in vivo, in order to develop, from isolated cells or stimuli intrinsic to the matrix, a new tissue for the restoration of the natural biological functions ${ }^{17,25}$.

Natural polymers present in the extracellular matrix are also used. Extracellular matrices are complex structures formed by proteoglycans, collagen and elastin. Due to their interaction with specific receptors on the cellular surface, they also participate in the processes that regulate the cells' phenotypic expression and, therefore, in the maintenance not only of the tissue's morphology and function, but also of its remodeling ${ }^{2}$, with a more outstanding role on bone tissue. Within this concept, a approximated effect is reached by the use of extracellular matrices formed by collagen and elastin, obtained from homologous or heterologous matrices, of which cells and other components responsible for non-desirable biological responses have been conveniently removed ${ }^{12,24}$.

The vast use of collagen ${ }^{3}$ in the field of biomaterials is associated to the natural properties that include low immunogenic response, even of heterologous origin, low toxicity, ability to promote cellular growth and adhesion, homeostasis, and the ability of the collagen solution to repair in vitro, in the interior of the microfibrillar structure, the same structure found in natural tissues ${ }^{1}$.

Chemical changes result in matrices loaded with collagen used as scaffold for cellular growth, such as, for example, the characterization of collagen acellular matrices, prepared from pericardium, intestinal submucosa and tendon, all of bovine origin; presenting various levels of deaminization through selective hydrolyses of the carboxyamide groups of asparagine (Asn) and glutamine (Gln) residues present in type I collagen chain- $\alpha$. They allow for the development of polyanionic collagen-based materials, with various physical-chemical properties and macromolecular settings on the formation of fibrillae $e^{5,6,22}$.

The anionic collagen obtained from the alkaline treatment has piezolectric properties, heterogeneous pores, and complete removal of intersatitial cells, and generates a biocompatible matrix, of which histological results show a low inflammatory response and induce bone formation in a small period of time. The low cost of production, associated to biocompatibility and osteoconductivity performance, make anionic collagen matrices promising alternatives for bone defect treatment ${ }^{21}$.

Nonetheless, among the materials used for constructing the matrices, there are differences in terms of the disposition of collagen fibers. After the treatment by hydrolysis, the piezoelectric matrix, rich in collagen and elastin, shows a different fiber disposition according to the chosen tissue. In the pericardium, the collagen fibers are entwined, while in the tendon, due to the natural characteristics, the collagen fibers are parallel to its long axis. It is indispensable to know about the orientation of collagen fibers in human tissues, such as bones, when studying the relation between physical properties and structures ${ }^{8,20}$.

Hence, this study was performed to analyze the biocompatibility of anionic collagen matrices, the local bone response following implantation in surgically-created bone defects, and the orientation of collagen fibers in the neoformed bone tissue. The anionic collagen matrices produced from pericardium and bovine tendon were already characterized by thermal analysis, infrared spectroscopy, titration and dielectric properties, as described in previous publications ${ }^{15,19}$. 


\section{Material And Method}

The study of biocompatibility and bone tissue response was performed in surgically-created defects of the tibia in rats. Seventy-two male adult Wistar rats (Rattus norvegicus albinus), weighing between 220 and $260 \mathrm{~g}$ were used in this experiment. The research was approved by the Research Ethics Committee of the University of Marília (Marília, São Paulo, Brazil).

For the experimental surgery, the rats were submitted to general anesthesia by intramuscular injection of Cetamine Hydrochloride $(75 \mathrm{mg} / \mathrm{kg}$ ) associated to Tiazine Chloridrate $(1,5 \mathrm{ml} / \mathrm{Kg})$. The animals were trichotomized at the ventral region of the posterior limb and antiseptic cleaning done with an iodine solution (10\%).

Next, using a surgical blade \#15, a $20 \mathrm{~mm}$ linear incision was made, longitudinal to the posterior limb, following divulsion of the muscular tissue surrounding the left tibia. The incision was extended to the periosteum obtaining a wide working area. With a \#8 steel round burr, mounted on a low rotation micromotor, a cavity of approximately $2.2 \mathrm{~mm}$ diameter was prepared, reaching the bone marrow in depth. The cavity was performed on the tibia's proximal portion under copious irrigation with a sterile solution of Sodium Chloride at $0.9 \%$.

The rats were divided into 4 experimental groups of 18 animals each:

a) Group 1 : Control Group, surgical cavity with no implant, filled only with blood clot; b) Group 2 : Pericardium medullar implant 12 hours; c) Group 3 : Tendon medullar implant 24 hours, with the biggest axis of its collagen fibers directed parallel to the tibia's biggest axis; d) Group 4 : Tendon medullar implant 24 hours, with the biggest axis of its collagen fibers directed perpendicular to the tibia's biggest axis.

In the experimental groups 2,3 , and 4 , each animal received the respective implant matrix, hydrated with sterile saline solution at $0.9 \%$. After placing the matrices or executing the empty defect, the divulsioned tissues were repositioned and sutured with 4-0 silk. During the postoperative period, the animals were kept in individual cages and received water and appropriate rat chow ad libitum.

Six animals of each group were sacrificed, by an excessive injection of the aforementioned anesthetic, in periods of 7,15 , and 30 days counted from the date of surgery. At the moment of sacrifice, the portion of the tibia containing the cavity was removed and fixed in formalin solution at $10 \%$ during 24 hours; they were then washed in running water for 12 hours and decalcified in E.D.T.A. (Ethylenediaminetetraacetic acid) solution at $20 \%$, during 5 weeks. The decalcifying solution that contained the samples was changed once a week.

Next, the samples underwent routine laboratorial process to be embedded in paraffin. After obtaining the blocks, semi-serial longitudinal sections were made, with a thickness of 6 micrometers in one rotating micrometer, and the obtained samples were stained with hematoxylin and eosin for the histomorphological study in light microscopy.

\section{Results}

\section{1 - Group G1 (Control)}

The histological study showed a fibrosis band on the superficial surgical area, highly present at day 7 and day 15 and reduced at day 30 . Under the fibrosis band, in contact with the medullar region, it was observed, starting on the $15^{\text {th }}$ day, the presence of primary bone tissue, forming a rudimentary immature neocortical, which within 30 days became thicker and more organized, with a more mature aspect. A defined periosteum, covering the neocortical, was not observed.

In addition, the medullar region also had connective tissue with no bone differentiation delimiting the area with recent bleeding at 7 days and inexistent at days 15 and 30. There was increased new bone formation in the period of 7 days, involving the area with fibrosis and blood, with increased intensity within 15 and 30 days.

Presence of infiltrated mononuclear inflammatory next to the new bone formation was observed, which increased in intensity, proportional to longer surgical time.

Vascular congestions, present among the immature bone trabeculae, with prevalence in the 15-day period.

\section{2 - Group G2 (Pericardium 12 H)}

The light microscopy study of the surgical area showed the presence of a more superficial fibrosis than that observed for group G1 and apparently more intense than day 15 . Presence of neocortical starting at day 15 with greater bone maturity at day 30 , with intensity similar to that observed in group G1.

On the medullar region, next to the implanted pericardium, presence of reactional fibrosis, only at day 7 

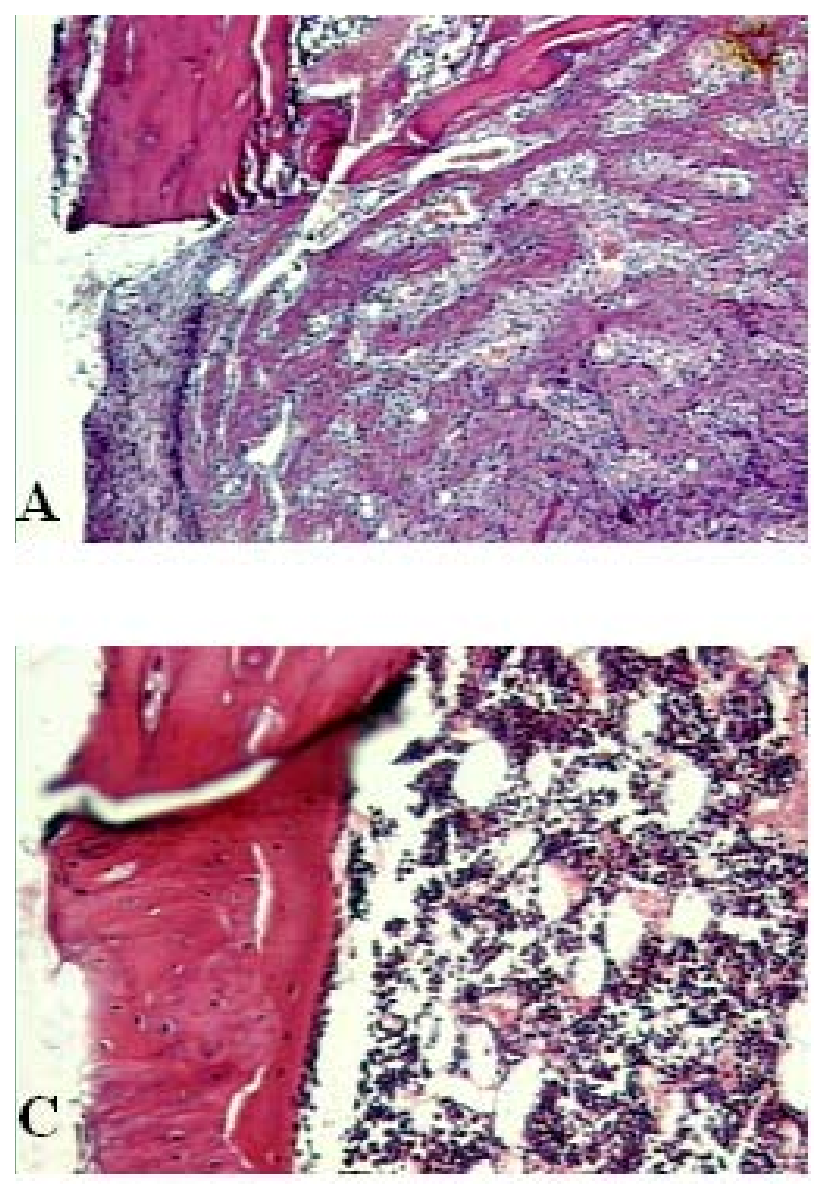

and new bone formation surrounding the pericardium, in all implant periods; however, less intense than in group G1. The vascular congestion on the neoformed bone, despite being less intense than that of group G1, also showed a greater increase at day 15 .

Accumulation of osteoblast and osteoclast cells on the distal extremities of the pericardium, with higher intensity at day 7.

The pericardial collagen fibers showed a multidirectional orientation in the medullar region and after 15 days there was a presence of slight new bone formation arently on its collagen fibers and with an increase of intensity at day 30 . Presence of infiltrated mononuclear inflammatory similar to G1.

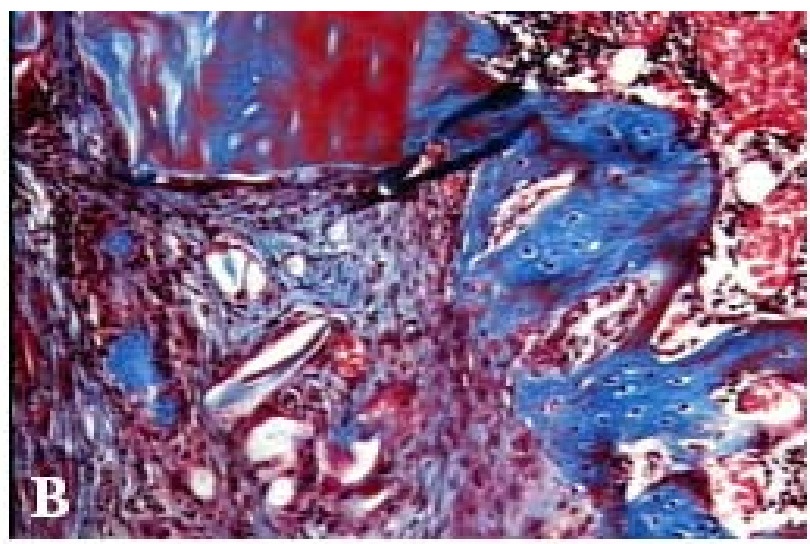

FIGURE 1 - Group G1 (Control). Hematoxylin and eosin. 7 days (A) 40X, 15 days (B) 100X and 30 days (C) 100X. Superficial surgical area: (A) and (B) Superficial fibrosis on residual cortical bone in continuity with medullar new bone formation. (C) Cortical new bone formation and medullar region with haematopoietic tissue bone marrow.

\section{3 - Group G3 (Parallel tendon 24 h)}

The superficial surgical area showed superficial fibrosis slighter than that observed in group G1; however, more intense than in group G2 and also more prominent at day 15. Presence of neocortical, starting at day 15 , with greater bone maturity at day 30 , with intensity lower than that observed in groups G1 and G2.

New bone formation and vascular proliferation surrounding the implant similar to group G2. Accumulation of osteoblast and osteoclast cells on the distal extremities of the tendon, of which intensity decreases with higher implant time. 

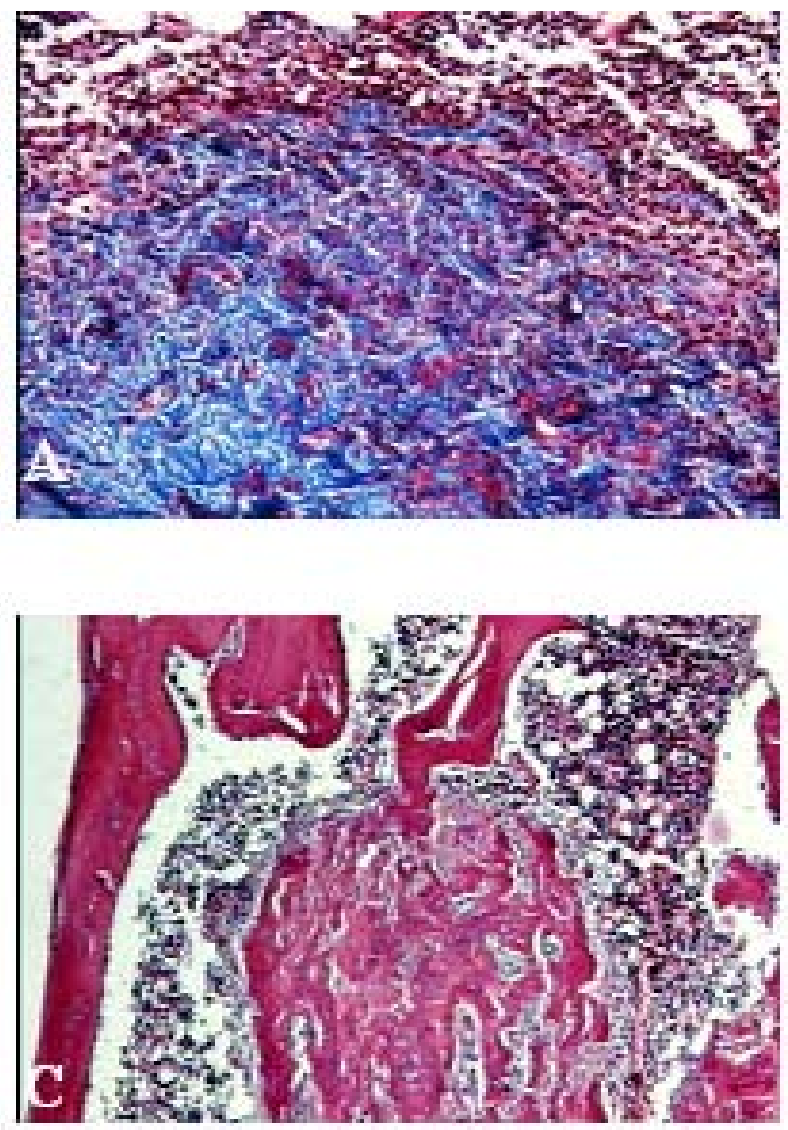

The tendon collagen fibers showed orientation parallel to the bone's largest axis, only at day 7 and a multidirectional arrangement that increases with implant time.

The new bone formation on the tendon's collagen fibers was found at day 7 of implantation and with growing intensity, proportional to implant time. Presence of infiltrated mononuclear inflammatory with intensity similar to groups G1 and G2.

\section{4 - Group G4 (Perpendicular Tendon 24 h)}

The microscopy study of the superficial surgical area showed presence of superficial fibrosis subtler than that observed in groups G1 and G3; however, similar to group G2, and also more prominent at day 15. Presence of neocortical starting at day 15 and with a greater bone maturity at day 30 , with intensity similar to that observed in groups G1 and G2.

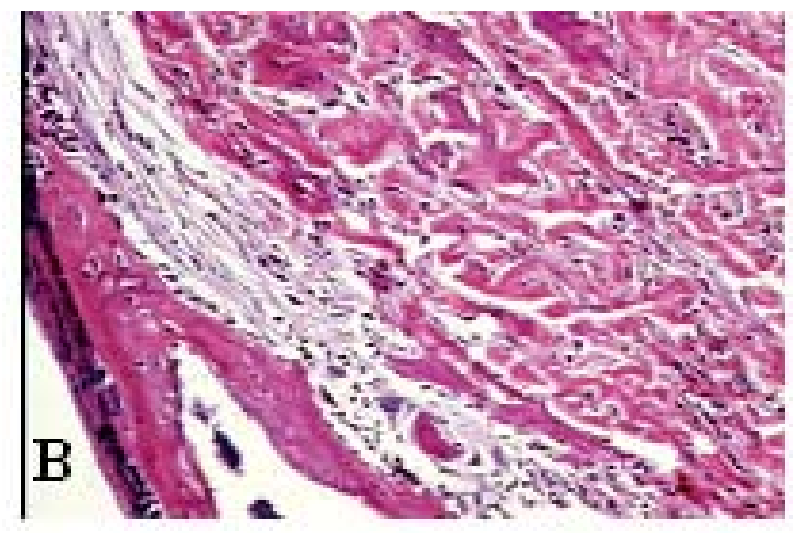

FIGURE 2 - Group G2 (Pericardium 12 h). Hematoxylin and eosin. 7 days (A) 100X, 15 days (B) 100X and 30 days (C) 40X. (A) Medullar region: haematopoietic bone marrow and pericardium.(B) and (C) Formed Neocortical and medullar region containing pericardium, with new bone formation in its interior, on its collagen fibers.
New bone formation greater than group G3 at day 7 and in an amount that grows with implant time. Moderate vascular proliferation, with no change of intensity with implant time.

Osteoblasts and osteoclasts in amounts similar to group G3 and located prevalently on the distal extremities of the tendon.

The implanted tendon showed multidirectional orientation of its fibers, starting at day 7 of implantation, and the perpendicular arrangement of the fibers in relation to the bone's greatest axis was less observed than for the surgical procedure.

New bone formation on the tendon collagen fibers starting at day 15 and more prominent at day 30 than in group G3.

The infiltrated mononuclear inflammatory and the interstitial fibrosis were present in the 3 implant periods, with intensity similar to the previous groups. 

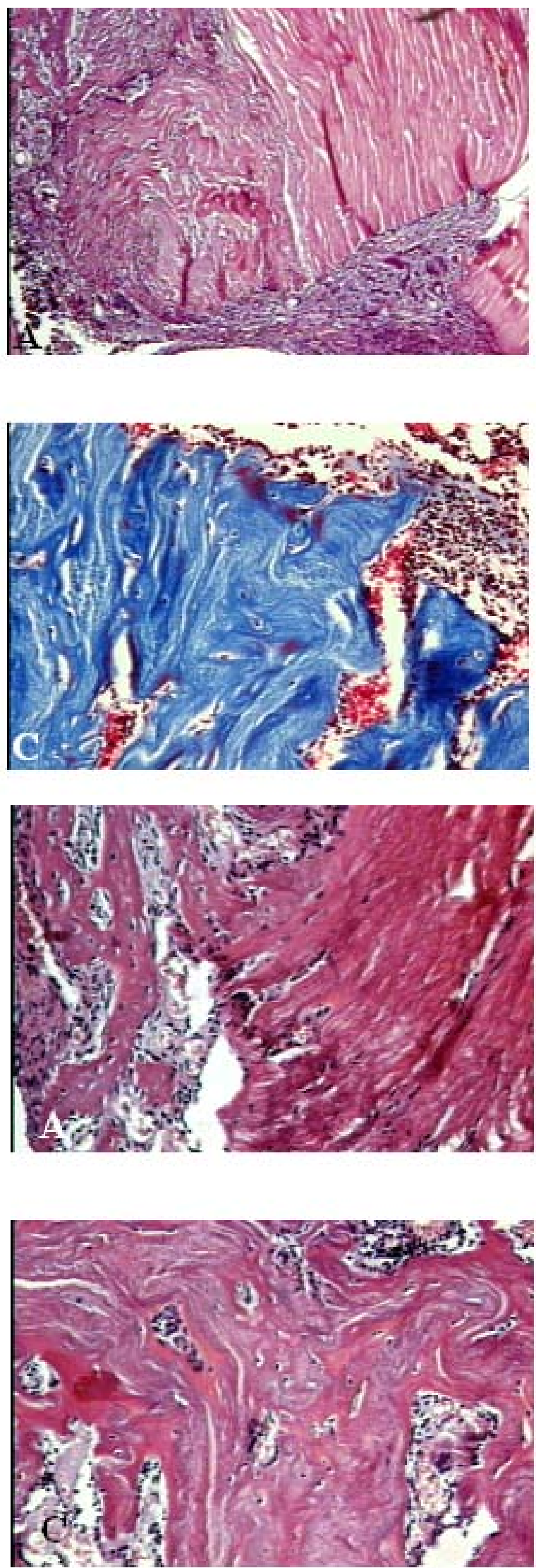

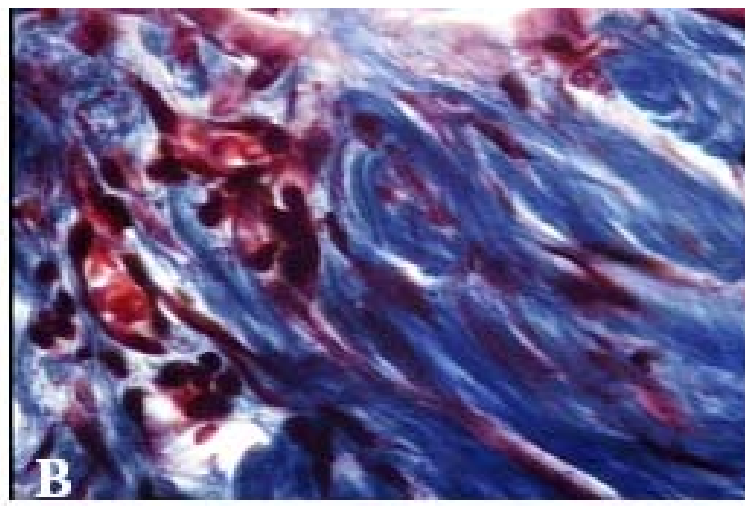

FIGURE 3 - Group G3 (Parallel tendon 24 h). Hematoxylin and eosin. 7 days (A) 40X, 15 days (B) 400X and 30 days (C) 100X

(A) and (C) Medullar region: noeformed bone on the implanted tendon.

(B) Transition between osteoblast cells and tendon. Presence of blood vessels penetrating between the tendon's collagen fibers.

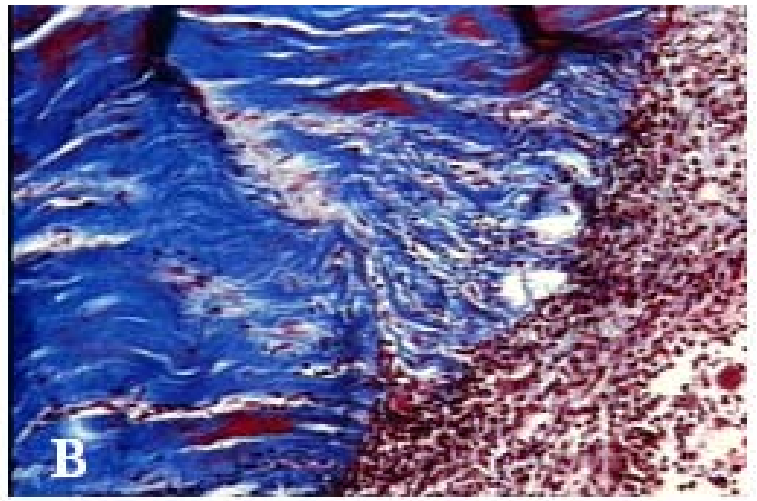

FIGURE 4 - Group G4 (Perpendicular tendon 24 h). Hematoxylin and eosin. 7 days (A) 100X, 15 days (B) 100X and 30 days (C) 100X.

(A) and (B) Medullar region: Transition between osteoblast cells and tendon Presence of blood vessels penetrating between the tendon's collagen fibers. (C) New bone formation on the tendon collagen fibers. 


\section{Discussion}

This study's results show that there was new bone formation in the interior of the anionic collagen threedimensional matrices, obtained through hydrolysis of fresh bovine pericardium and tendon. Hence, it is verified that this biomaterial presents properties that are in agreement with the principle that artificial matrices, of synthetic nature or derived from natural materials, independent of its origin, have the ability of sustaining cellular growth ${ }^{17,25}$.

The hydrolysis process provided the complete removal of cells from the matrices. The presence of cells is one of the main causes of failure in its application, causing dystrophic calcification, intense inflammatory response, and foreign body reaction. The results demonstrated the lack of dystrophic calcification and foreign body reaction, besides a low initial inflammatory response, confirming that there was removal of cells through hydrolysis ${ }^{21}$.

Hydrolysis provides the opening of spaces, creation of channels and pores, which transform the dense structure of the bovine collagen matrix into a spongelike structure, favoring cellular migration, observed in this study, which is in agreement with other researches that used this treatment ${ }^{5,6,21,25}$.

The matrices used in this study, independent of the size of pores, presented a continuous and interconnected pore network, which allowed cellular migration of erythrocytes and osteoblasts to the interior of the implant; as previously observed by Rocha, et al. ${ }^{21}$. Since bone grafts are avascular and depend on diffusion, cellular repopulation, observed with 7 days of implantation, could impede, in large defects, the graft from being resorbed before complete osteogenesis ${ }^{9,13}$. One of the graft's main characteristics is that its degradation speed must be compatible with the growth speed of the tissue for which it serves as scaffold ${ }^{7,10,11,16}$.

The inflammatory response observed in Group 1 , in which the surgical cavity was filled only with a blood clot, was similar to Groups 2, 3, and 4, which received anionic collagen implants. All biomaterials trigger an inflammatory response in the host. This response usually extends for a period of time longer than that observed for the repair of a cavity filled only with a blood clot, which in this study provided the determination of the role of collagen matrices in the inflammatory phase of the healing process ${ }^{4,21}$.

Rapid osteogenesis, with the integration of the graft to the host, in a short period of time, constitutes a clear advantage of anionic collagen in relation to other biomaterials, in accordance to Rocha, et al. ${ }^{21}$ and Rosa, et al. ${ }^{22}$.
Another favorable factor of the anionic collagen, as reported by the aforementioned authors, was that at 30 days, in spite of a moderate degeneration of the collagen fibers of the implant material, no evidence of resorption was found, which suggests the incorporation of the material by the neighboring tissues, and an eventual resorption must be associated to the remodeling during bone healing.

The new electrical charge of collagen could affect the behavior of cells and the distribution of extracellular tissue components. Firstly, the charges modified the collagen fibrils assembly, thus changing the way binding sites are exposed to tissue environment. Osteoblasts are known to attach directly to collagen through integrin-RGD (-arg-gly-asp-) site interaction. It is possible that the three-dimensional rearrangement of collagen could have affected the distribution of RGD sites in the new macro-molecular configuration of the matrices. Secondly, the osteoblasts are probably attracted by the density of negative charges and inclusion of growth factors ${ }^{3,21}$.

In this study, the osteoblasts migrated to the interior of the graft, initially obeying the arrangement of the collagen fibers, which showed to be assembled to the bovine pericardium matrix and with a parallel disposition on the tendon. With the growth of bone formation in the interior of the matrix, the arrangement becomes multidirectional in both materials. In group 4 , in which the graft was positioned perpendicularly to the long axis of the rat's tibia, at day 7, a change in the direction of the material was observed, with a beginning of new bone formation. Osaki, et al. ${ }^{20}$ demonstrates a two-dimensional direction of orientation of collagen fibers in the human calcaneous and suggests that the direction and degree of orientation are intimately related to the direction and magnitude of the stress employed on the bone, respectively.

The study performed by Bromage, et al. ${ }^{8}$ used human and non-human bones. Differences could be observed in terms of the position of the animal in relation to the ground. In animals that position similar to rats, there is a prevalence of deposition of collagen in a longitudinal orientation, in primary tissues deposited during growth as well as in secondary and remodeled bones. The longitudinal orientation of collagen is probably an adaptation to tension and employed strength. The human femur demonstrated a preference for transversal orientation of collagen fibers in areas corresponding to high compression and longitudinal in areas of high tension. Many factors may influence the orientation of collagen fibers, such as race, sex, age, 
growth trajectory, metabolic and nutritional status, status of health or disease, positioning, etc.

The clinical limitation is its use in large orthopedic defects, because the pericardium is originally of small thickness. In this case, the tendon in indicated, for it has a great pattern of length and thickness, and can be obtained in different forms and from various origins. The tendon, used in groups 3 and 4, showed faster and more intense new formation in group 4. According to what was observed on the laminae, this is probably due to the form of insertion in the surgically-created defect. When placed perpendicularly to the long axis of the tibia, the tendon's free extremities are open to the periosteum and for the medullar, sources of indifferenced cellular elements, which, if stimulated, are differenced in osteoblasts and promote new formation. This form of insertion facilitates the access of cells, including the neovascular, to the interior of the graft. Therefore, this study's matrices showed a high po- tential for clinical use, as they are biocompatible and promote bone formation and the possibility of use in both small and large orthopedic defects.

\section{Conclusion}

Within the conditions established in this study, it is concluded that:

a) The implanted matrices are biocompatible.

b) The implants function as a three-dimensional matrix that induces bone formation

c) The tendon implanted with fibers perpendicular to the larger axis of the bone has a higher potential of inducing new bone formation.

d) Initially, cellularity accompanies the arrangement of collagen fibers, obtaining a progressive multidirectional arrangement.

\section{Resumo}

Este estudo apresentou como objetivo, examinar a biocompatibilidade de matrizes de colágeno aniônico, sua resposta óssea local após implantação em defeitos ósseos criados cirurgicamente e a influência da orientação das fibras colágenas no tecido ósseo neoformado. Foram utilizados 72 ratos (Rattus norvegicus albinus) divididos em 4 grupos experimentais de 6 animais cada: Grupo 1 (Controle), sem implante; Grupo 2, implante medular de pericárdio 12 horas; Grupo 3, implante medular de tendão 24 horas, com o maior eixo de suas fibras colágenas direcionados paralelamente ao maior eixo da tíbia e, Grupo 4, implante medular de tendão 24 horas, com o maior eixo de suas fibras colágenas direcionados perpendicularmente ao maior eixo da tíbia. A evolução do processo de reparo, após a cirurgia experimental, foi avaliada microscopicamente com 7, 15 e 30 dias pós-operatórios. Os resultados demonstraram que as matrizes implantadas são biocompatíveis e funcionam como uma matriz tridimensional induzindo a formação de osso, maior no grupo 4 . A celularidade, inicialmente, acompanha o arranjo das fibras colágenas, adquirindo um arranjo multidirecional crescente.

\section{UNITERMOS}

Colágeno; regeneração óssea; osteogênese; biocompatibilidade; tendão.

\section{References}

1. Alberius P. Role of osteopromotion in experimental bone grafting to the skull: a study in adult rats using a membrane technique. J Oral Maxillofac Surg. 1992;50:829-34.

2. Alberts B, Bray D, Lewis J, Raff M, Roberts K, Watson JD. Molecular biology of the cell. New York: Garland Publishing; 1994. 971-95.

3. Anselme K. Osteoblast adhesion on biomaterials. Biomaterials. 2000;21(7):667-81

4. Bennett S, Connolly K, Lee DR, Jiang Y, Buck D, Hollinger JO, et al. Initial biocompatibility studies of a novel degradable polymeric bone substitute that hardens in situ. Bone. 1996;19:101S-7S.
5. Bet MR, Goissis G, Lacerda CA. Characterization of polyanionic collagen prepared by selective hydrolysis of asparagines and glutamine carboxyamide side chains. Biomacromolecules. 2001;2(4):1074-9.

6. Bet MR, Goissis G, Vargas S, Selistre-de-Araujo HS. Cell adhesion and cytotoxicity studies over polyanionic collagen surfaces with variable negative charge and wettability. Biomaterials. 2003;24(1):131-7.

7. Braddock M, Houston P, Campbell C, Ashcroft P. Born again bone: tissue engineering for bone repair. News Physiol Sci. 2001;16(5):208-13.

8. Bromage TG, Goldman HM, McFarlin SC, Warshaw J, Boyde A, Riggs $\mathrm{CM}$. Circularly polarized light standards for investigations of collagen fiber orientation in bone. Anat Rec. 2003 Sep;274B(1):157-68. 
9. Brown KLB, Cruess RL. Bone and cartilage transplantation surgery. J Bone Joint Surg Am. 1982;64-A:270-9.

10. Burg KJL, Porter S, Kellam JF. Biomaterial developments for bone tissue engineering. Biomaterials. 2000;21:2347-59.

11. Croteau S, Rauch F, Silvestri A, Hamdy RC. Bone morphogenetic proteins in orthopaedics: from basic science to clinical practice. Orthopaedics. 1999;22:686-95.

12. Delustro F, Dasch J, Keefe J, Ellingsworth L. Immune responses to allogeneic and xenogeneic implants of collagen and collagen derivatives. Clin Orthop. 1990;260:263-79.

13. Enneking WF, Eady JL, Burchardt H. Autogenous cortical bone grafts in the reconstruction of segmental skeletal defects. J Bone Joint Surg Am. 1980;62-A:1039-58.

14. Folkman J, Haudenschild C. Angiogenesis in vitro. Nature. 1980;288:551-6.

15. Goissis G, Piccirili L, Goes JC, Plepis AMD, Das-Gupta DK. Anionic collagen: polymer composities with improved dielectric and rheological properties. Artif Organs. 1998;22:203- 9.

16. Harakas NK. Demineralized bone-matrix-induced osteogenesis. Clin Orthop Rel Res. 1984;188:239-51.

17. Hench LL. Biomaterials: a forecast for the future. Biomaterials. 1998;19:1419-23.

18. Kim BS, Mooney DJ. Development of biocompatible synthetic extracellular matrices for tissue engineering. Trends Biotechnol. 1998; 16:224-9.

19. Lacerda C, Plepis AMG, Goissis G. Selective hydrolysis of carboxyamides of aspargine and glutamine residues of collagen: preparation and characterization of anionic collagen matrices for biomaterial applications. Quim Nova. 1998;21:267-71

20. Osaki S, Tohno S, Tohno Y, Takakura Y. Determination of the orientation of collagen fibers in human boné. Anat Rec. 2002 Feb 1;266(2):103-7.
21. Rocha LB, Goissis G, Rossi MA. Biocompatibility of anionic collagen matrix as scaffold for bone healing. Biomaterials. 2002;23(2):449-56.

22. Rosa FP, Lia RCC, Souza KOF, Goissis G, Marcantonio Jr E. Tissue response to polyanionic collagen: elastin matrices implanted in rat calvária. Biomaterials. 2003;24(2):207-12.

23. Tiedeman JJ, Garvin KL, Kile TA, Connolly JF. The role of a composite, demineralized bone matrix and bone marrow in the treatment of osseous defects. Orthopaedics. 1995;18:1153-8.

24. Valente M, Ius P, Bortolotti U, Talenti E, Bottio T, Thiene G. Pathology of the Pericarbon bovine pericardial xenograft implanted in humans. J Heart Valve Dis. 1998;7:180-9.

25. Widmer MS, Gupta PK, Lu L, Meszlenyi RK, Evans GR, Brandt $\mathrm{K}$, et al. Manufacture of porous biodegradable polymer conduits by an extrusion process for guided tissue regeneration. Biomaterials. 1998;19:1945-55.

26. Younger EM, Chapman MW. Morbidity at bone graft donor site. J Orthop Trauma. 1989;3:192-5.

Recebido em: 05/01/07

Aprovado em: 13/08/07

Rogério Leone Buchaim UNESP - University of Sao Paulo State School of Dentistry of Aracatuba Department of Basic Sciences R. José Bonifácio 1193, 16015-050, Sao Paulo, Araçatuba, Brazil Tel.: (+55) 18- 36363200 r. 3459/3434 E-mail address: rogerio@foa.unesp.br 